\title{
Comparison study of multistep forging and injection forging of automobile fasteners
}

\author{
Senyong Chen ${ }^{\mathrm{a}}$ and Yi Qin \\ Dept. of Design, Manufacture \& Engineering Management, The University of Strathclyde, \\ Glasgow G1 1XJ, UK
}

\begin{abstract}
In order to improve production efficiency, injection forging as a feasible approach was introduced to automobile fasteners production. In the study reported in this paper, two forging approaches, traditional multistep forging and injection forging, were analysed by using a finite element method. Using ABAQUS and DEFORM, some significant factors, namely, forging force, energy consumption, component accuracy and stress distribution in the die, were compared to explore the potential and challenge for this new forging approach. Morrow's stress life model was applied for the analysis of a die insert made of Tungsten Carbide ( $75 \% \mathrm{~W}$ and $25 \% \mathrm{Co}$ ). It is argued that the presently reported approach is helpful in analysis of forging.
\end{abstract}

\section{Introduction}

Cold forging is one of the best-known manufacturing processes for fabricating metal-components. Compared with other forming methods, it is well known that cold forging provides greater accuracy, better surface finish, lower consumption of material and enhancement of mechanical properties [1]. Because of these advantages, it is used widely to form automobile parts, especially for symmetrical components. Currently, most auto fasteners are produced by cold forging processes, specifically by traditional extrusion and heading. Through the use of these processes, efficiency, cost and quality, which always take the first place in production, have kept within certain limits. However, with increasing global competition, these conventional forging processes are facing challenges. Injection forging, therefore, was developed as a new forming option [2]. By employing this forging process, the process chain could be shortened, post processing reduced and the use ratio of the material improved [3].

To date, the works done on injection forging has been carried out largely by researchers. Balendra and Qin defined the formability limit in bulk forming, where the maximum aspect ratio of primary deformation zone (pdz) was found to be 1.64: attempts to exceed this limit led to instability in the workpiece [4]. In their subsequent research, it was found that the range of the pdz was required to be reduced to 1.3 to prevent surface-folds. In order to extend forming limits, some approaches, such as the use of a preformed billet [5] and a "truncated-conical" die [6], were proposed. A series of large thickness

\footnotetext{
${ }^{a}$ Corresponding author: senyong. chen@strath.ac.uk
}

This is an Open Access article distributed under the terms of the Creative Commons Attribution License 4.0, which permits unrestricted use, distribution, and reproduction in any medium, provided the original work is properly cited. 


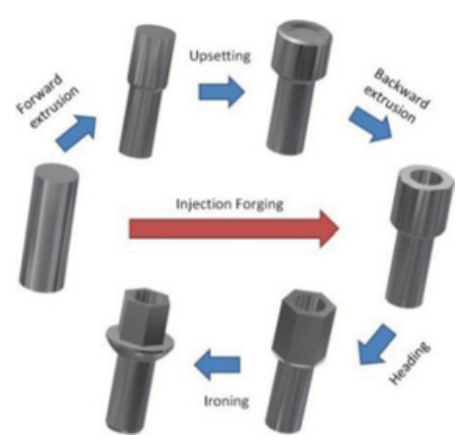

Figure 1. Illustration of the traditional forging process and the injection forging process.

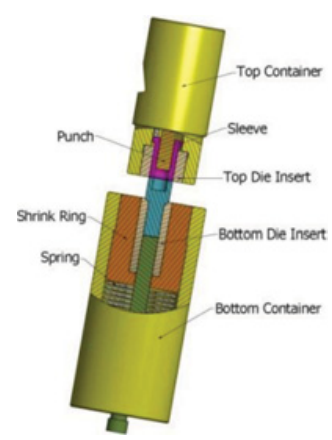

Figure 2. Tool configuration of injection forging.

flanges were successfully formed by these methods. However, foregoing utilizations of injection forging were located mostly within the research area, with a low forming speed and small quantities. The highspeed mass-production injection forging of auto fasteners remained unexplored.

In this study, two forging processes, multistep forging and injection forging, were compared in the forming of a hexagon bolt. A series of finite-element simulations were carried out to obtain reliable predictions of forging force, part accuracy and tool stress for each process. Based on these results, the component quality and tool life were analysed. According to these comparisons, the advantages and challenges of injection forging in auto fasteners production have been demonstrated.

\section{Process and materials}

Figure 1 presents a conventional multistep cold forging process in hexagon bolt forming. To secure the final forged hexagon bolt, the initial billet experiences five steps. In the first operation, round bar is extruded forwards to reduce the diameter in the bottom part, and is upset in the second operation. After this, the head is compressed by the punch to form a cavity. Before the final operation, the hexagon head is beginning to take a shape close to that of the required final shape. In this stage, the punch undergoes larger compressive stress, especially in respect of the forming of sharp corners. The last operation is ironing to finish the bottom and middle part of the hexagon bolt.

In order to shorten the process chain, injection forging is introduced. As can be seen from Fig. 1, the first three operations of tradition forging are replaced by injection forging. In other words, the initial billet is formed to the intermediate product with a cavity directly by radial and forward metal flow. Figure 2 shows the tool configuration of injection forging. In this design, a die spring is put into use to absorb the impact force from the punch to some extent. After forging, the die spring can restore the shrink ring to its initial position.

AISI 1010 was selected as the workpiece material in this study. The stress-strain relationship of AISI 1010 is presented below [7]:

$$
\bar{\sigma}=759 \bar{\epsilon}^{0.24} \quad(\mathrm{MPa})
$$

The material of die insert, shrink ring and container was WC, AISIH13 and AISI D3, respectively. The mechanical properties of these materials are listed in Table 1. 
Table 1. Material mechanical properties.

\begin{tabular}{|c|c|c|c|c|}
\hline Material & Hardness & $\begin{array}{c}\text { Young's } \\
\text { Modulus } \\
\text { (MPa) }\end{array}$ & $\begin{array}{c}\text { Yield Stress } \\
\text { (MPa) }\end{array}$ & $\begin{array}{c}\text { Poisson's } \\
\text { ratio }\end{array}$ \\
\hline WC & 67 HRC & 553000 & 2700 & 0.24 \\
\hline AISI H13 & 47 HRC & 212000 & 1200 & 0.3 \\
\hline AISI D3 & 60 HRC & 205000 & 930 & 0.285 \\
\hline
\end{tabular}

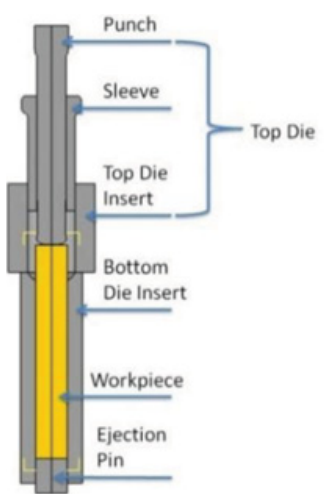

(a)

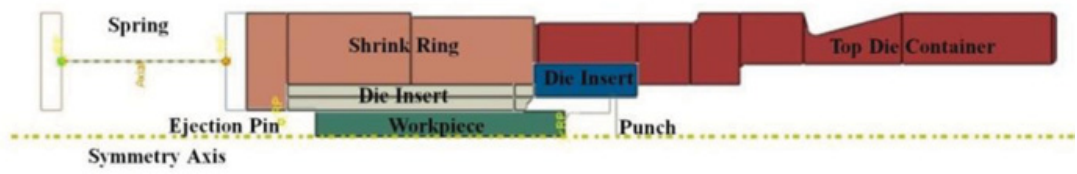

(b)

Figure 3. FE model of injection forging: (a) with DEFORM, and (b) with ABAQUS.

\section{Procedure}

The FE simulations were conducted using two kinds of software. The first one was DEFROM-3D which was employed to analyse the forging force. In this software, the workpiece was treated as a rigid-plastic body, and other parts were assumed to be rigid bodies. Only one quarter of the billet was meshed and simulated to save computational time. In order to examine the stress distribution and part accuracy during the forging processes, ABAQUS/Explicit was selected as a second software. Different from the model in DEFORM, an elastic-plastic body was applied for most of the parts with the exception of the punch, which was treated as a rigid body. Two-dimensional (axisymmetric) models were carried out in ABAQUS. The Arbitrary Lagrangian-Eulerian (ALE) method was used to maintain a good mesh quality in the workpiece. Enhanced hourglass control was applied to prevent the hourglass effect. A die spring was introduced to the injection forging model in ABAQUS, the stiffness of which was taken as $720 \mathrm{~N} / \mathrm{mm}$. All of the models complied with the following simulation step: moving the top die (in contact with the punch), the sleeve, and the die insert at the same velocity $(46 \mathrm{~mm} / \mathrm{s})$ until the workpiece was formed to full size. During this step, the ejection pin remained stable. According to [8], the coefficient of friction was set as 0.11 in the simulations. Figure 3 shows the FE model of injection forging in DEFORM and ABAQUS.

In order to predict the tool life, Morrow's stress life formula is applied. The equation is listed below:

$$
\frac{\sigma_{a}}{2}=N_{f}\left(\sigma_{f}^{\prime}-\sigma_{m}\right)^{b} \quad(\mathrm{MPa})
$$

$\sigma_{a}$ are $\sigma_{m}$ the stress amplitude and mean stress respectively, both of which depend on the maximum stress and minimum stress on the tool during the simulation. The fatigue strength coefficient $\sigma_{f}^{\prime}$ and 


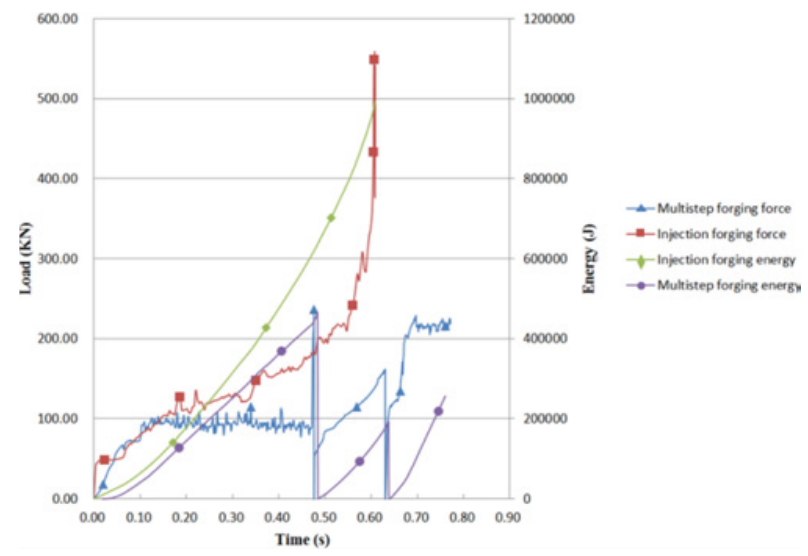

Figure 4. Load-energy-time curves for multistep forging and injection forging.

fatigue strength exponent $\mathrm{b}$ are material constants, which are obtained from [9]. $\mathrm{N}_{f}$ is the lifecycle number for the tool.

\section{Results and discussion}

\subsection{Forging forces and energy consumption}

Based on simulation results from DEFORM, the comparison of forging force is shown in Fig. 4. During the injection forging, the force basically continues to increase until $556.36 \mathrm{kN}$ at the end of the stroke. As for multistep forging, the peak value appears at the end of stage 1 , which is $236.52 \mathrm{kN}$. In the views of energy cost for a single-stage forming, the injection forging needs more energy than that in the multistep forging setup. Comparing with tradition forging, injection forging requires a more powerful forging press. Also, this indicates that the tooling of injection forging bears more severe loading because of the great forging force requirement.

\subsection{Component accuracy}

In order to compare the component accuracy, each of the coordinates of boundary points is extracted from ABAQUS simulation, as shown in Fig. 5. As can be seen from this figure, the evident difference is focused on the top part of the workpiece, caused by volume lost during the FE simulation as a result of the application of ALE adaptive mesh. Therefore, more punch displacement is required in FE simulation than that in a practical production. Because this comparison mainly focuses on radial errors at region A, C and axial errors at region B (refer to Fig. 5), this computational error is acceptable in the present study.

Figure 6 demonstrates the deformed component profile at region A, B and C for multistep forging and injection forging. During multistep forging, the radial error distribution at region A is uniform. The maximum radial error is about $58.4 \mu \mathrm{m}$ and the minimum value stays at $49.9 \mu \mathrm{m}$. For injection forging, the maximum error $(134.23 \mu \mathrm{m})$ appears at the bottom part of region A, caused by high stress concentration on the tool. After the peak error, this value reduces to $68.57 \mu \mathrm{m}$. In region $\mathrm{C}$, the product of multistep forging is closer to the target dimension, which has a peak value of $20.1 \mu \mathrm{m}$. However, the same value in injection forging can reach to $69.4 \mu \mathrm{m}$. In respect of axial error, injection forging exceeds multistep forging, the maximum errors being $8.4 \mu \mathrm{m}$ and $36.9 \mu \mathrm{m}$, respectively. This suggests that multistep forging may make a more accurate component in the radial direction. However, injection 


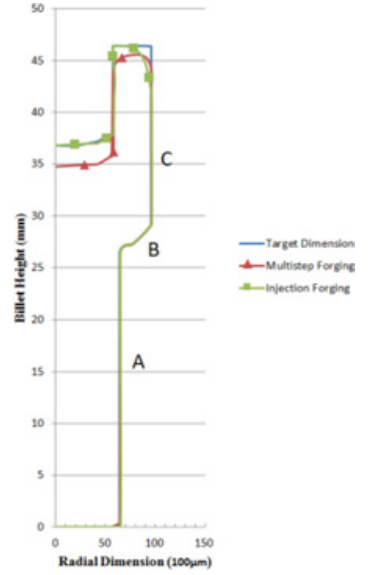

Figure 5. Comparison of component errors based on the FE simulation.
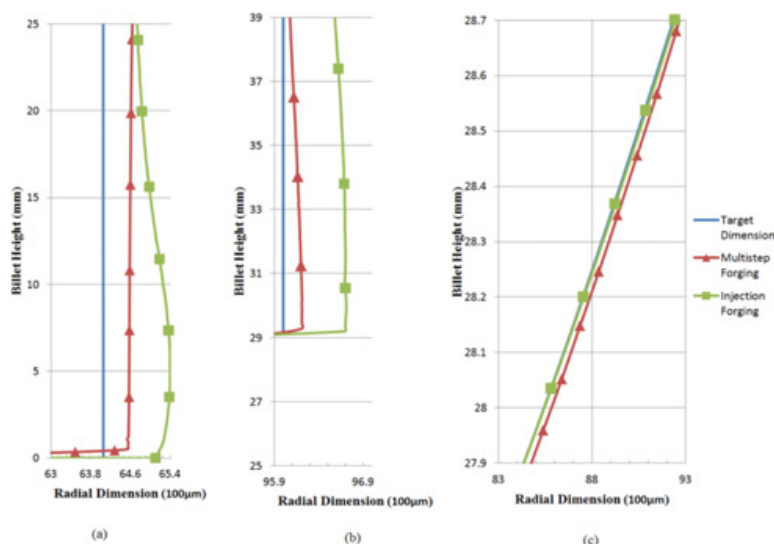

Figure 6. Component error at different regions: (a) radial error at region A; (b) radial error at region $\mathrm{C}$; (c) axial error at region $\mathrm{B}$.

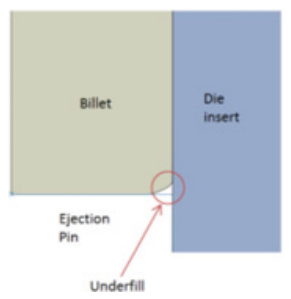

(a)

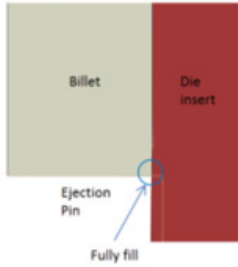

(b)

Figure 7. (a) Underfill in multistep forging; (b) Fully fill in injection forging.

forging has more advantage in respect of axial-direction. Additionally, in terms of underfill, it is obvious that the material still cannot fully fill the bottom die-cavity during the simulation. However, underfill is avoided in injection forging via different metal flow. In this case, it can be stated that injection forging is useful for solving this kind of component defect.

\subsection{Stress analysis and tool life prediction}

In multistep forging, the maximum Mises effective stress is $1804 \mathrm{MPa}$ in the first operation (forward extrusion), which indicates that forward extrusion is the most critical operation in multistep forging. Figure 8 shows the axial stress in the die inserts which are applied in forward extrusion and injection forging, respectively. There are two tensile stress concentration regions where it is possible to grow cracks. It is possible that a crack not only appears in the die cavity, but also grows in the external wall of the die insert.

For injection forging, the maximum Mises effective stress is extremely high, attaining a value of $2700 \mathrm{MPa}$ (refer to Fig. 9). In other words, plastic deformation may occur in the die insert during forging. This is a main challenge to deter injection forging from being used in practice. Currently, there are two possible approaches to solve this problem. One is to reduce the friction force during forging by the application of an excellent lubrication. Another is to reduce the flow stress of material by appropriately increasing temperature. Compared with the latter approach, reduction of friction force is easier to realize. 


\section{MATEC Web of Conferences}

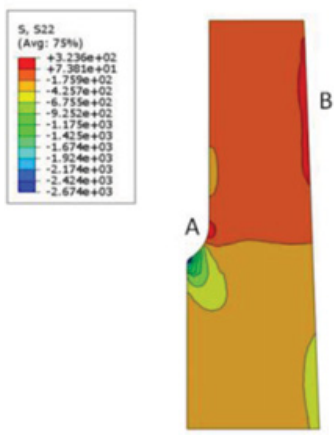

(a)

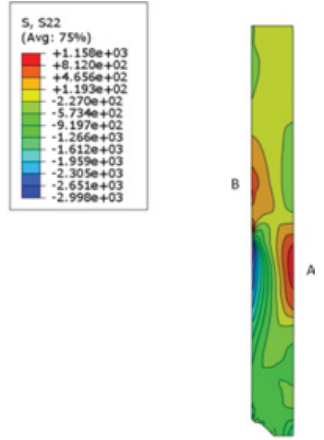

(b)

Figure 8. Axial stress at the end of the forging stoke: (a) Multistep forging, (b) Injection forging.

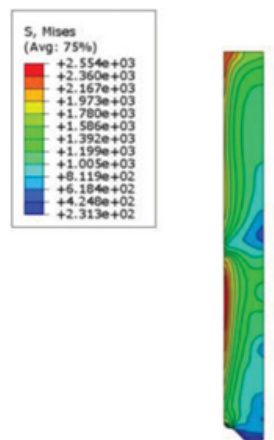

(a)

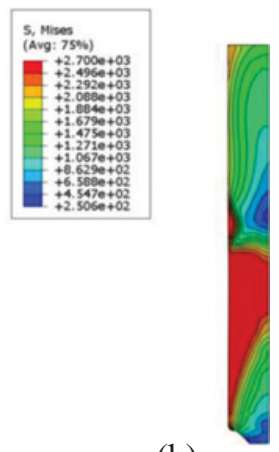

(b)
Table 2. Tool life prediction.

\begin{tabular}{|l|c|}
\hline Forging approach & Life prediction \\
\hline $\begin{array}{l}\text { Multistep Forging: } \\
\text { Operation 1 }\end{array}$ & $1,037,841$ \\
\hline $\begin{array}{l}\text { Multistep Forging: } \\
\text { Operation 1 }\end{array}$ & $4,226,094$ \\
\hline $\begin{array}{l}\text { Multistep Forging: } \\
\text { Operation 1 }\end{array}$ & $2,312,306$ \\
\hline $\begin{array}{l}\text { Injection Forging } \\
(\mathrm{COF}=0.11)\end{array}$ & 168,699 \\
\hline $\begin{array}{l}\text { Injection Forging } \\
(\mathrm{COF}=0.05)\end{array}$ & 789,245 \\
\hline
\end{tabular}

Figure 9. Die stress distribution for different coefficients of friction: (a) 0.05 ; (b) 0.11 .

Figure 9 shows the same die insert under different friction conditions. The maximum stress has a large reduction to $2500 \mathrm{MPa}$ when the coefficient of friction is 0.05 .

Regarding tool life, Table 2 shows the predicted value for injection forging and multistep forging. Generally speaking, tool design favours multistep forging for high volume production. Even through the tool life for operation 1 is lowest, it still can attain 1,037,841 lifecycles. However, for injection forging, the high die stress seriously impairs the tool life, which is only 168,699 lifecycles. Obviously, this short tool life cannot meet the industrial requirements. It is worth noting that the tool life has a substantial improvement when the COF reduces to 0.05 . This suggests that injection forging has a potential to replace multistep forging when it employs excellent workpiece-to-die interfacial conditions.

\section{Conclusions}

In this study, injection forging and traditional multistep forging were compared in the forming of automobile fasteners. The study shows that injection forging brings some benefits to the forging, such as, saving tooling manufacture cost and improvement in forging efficiency. Additionally, the component accuracy is ideal in the axial direction, and underfill is prevented by this approach. However, several problems are correspondingly caused by introducing this short process chain. The main problem is high die-stress and unsatisfactory tool life caused by the presence of great forging force. Accordingly, the 
simulation indicates that the coefficient of friction has a significant effect on die stress and tool life. Therefore, improving the friction condition in injection forging has to be investigated in the future.

\section{References}

[1] K. Lange, Handbook of metal forming. p. P8.61 (1985)

[2] R.M. Cogan, "Hydrodynamic compression forging" (1963)

[3] T. Nakano, "Modern applications of complex forging and multi-action forming in cold forging," J. Mater. Process. Technol., 46, pp. 201-226 (1994)

[4] R. Balendra and Y. Qin, "FE simulation of the development of flaws during injection forging," Int. J. Mach. Tools Manuf., 34, no. 8, pp. 1091-1101 (1994)

[5] R. Balendra and Y. Qin, "Material-flow Considerations for the Design of Injection Forging," J. Manuf. Sci. Eng., 119, no. 3, pp. 350-357 (1997)

[6] J. Richert, "Stability conditions of metal flow in radial extrusion," Zeitschrift fur Met., 79, pp. 248251 (1988)

[7] Y. Lee et al., "Analysis of the elastic characteristics at forging die for the cold forged dimensional accuracy," J. Mater. Process. Technol., 130-131, pp. 532-539 (2002)

[8] Q. Zhang et al. "Evaluation of friction condition in cold forging by using T-shape compression test," J. Mater. Process. Technol., 209, no. 17, pp. 5720-5729 (2009)

[9] M.A. Saroosh et al., "High cycle fatigue life prediction of cold forging tools based on workpiece material property,” J. Mater. Process. Technol., 191, no. 1-3, pp. 178-181 (2007) 